\title{
The Characteristics of Artistic Styles Research in the Age of Digital Fashion Illustration
}

\author{
Chunlan Huang \\ The Fashion Design and Management branch \\ Jiangxi Institute of Fashion Technology \\ Nanchang, China \\ 2008huangcl@163.com
}

\author{
Ruijuan Ren \\ The Fashion Design and Management branch \\ Jiangxi Institute of Fashion Technology \\ Nanchang, China \\ ranusren@hotmail.com
}

\begin{abstract}
The arrival of the age of digital developed fashion illustration to be more characteristic in the new era. The article found a entry point of the features of digital illustrations to research the art style at the present times through the two aspects of the medium expression and the art styles of digital fashion illustration. The aim is to make the characteristics of digital fashion illustrations sharp and valuable.
\end{abstract}

Keywords-digital, fashion, illustration, art style, medium.

\section{INTRODUCTION}

With the development of continually enhanced human technology, especially digital products make our lives more colorful. In the meantime, digital fashion illustrations emerged as the times require with the development of digital software. It gives the traditional illustrations a new life, while makes people feel its characteristics features of modern time and a brand new vision experience.

Clothing is one part of fashion; illustration is the most vivid expressions in graphic design. When clothing and illustration meet, they will definitely makes fashion design more attractive. Illustration means: "the picture in the books or magazines, some were printed in the certre of the text, some as a insert page, the role is supplementary instruction for text, or artistic appreciation", which defined by Chinese dictionary CiHai. The usage of illustration is to print pictures in the texts in a reasonable way to show an explanation of the texts and make texts more attractive and infectious, while it will bring a vision feast and infinite imagination to people. So what's the concept of digital fashion illustration? Obviously, it is a fine art that aims to garments as an object to express fashion design forms and overall looks through the method of artistic process via the medium of digital technology. Enters for the 21st century, the application of digital technology in fashion industry became more popular along with the arrival of the digital age. With the medium of brand-new computer software, fashion illustration has developed from traditional hand drawing to computer-aided design which is becoming increasingly popular among the artists because of the advertise that is digital drawing is more convenient and revisable. Nowadays, there is a new trend that developing new technology of digital to express illustrators' personal performance and various styles.

The characteristic of digital illustration is richness. That is to say, there are hundreds and thousands of forms to express its abundance such like the richness of the methods of collecting inspirations and the different tools as a medium. For example, there are many different kinds of painting brushes in Adobe Photoshop, which create a realistic-looking effect. In addition, CorelDraw, Painter, and Illustrator are also very professional painting software. More specifically, Illustrator's watercolor brushes can generate a vivid flower cloth. The Bezier tool in CorelDraw can create pictures and structures clearly. The combination of Painter and Wacom is like a masterpiece. If we combine all of these software mentioned above, the expression of painting will be varied beyond imagination. The richness of digital fashion illustrations can also be expressed in correcting sketches. If customers want to revise some details of the illustration, it allows illustrator works in the original file. To compare with the traditional painting, the new technology saves lots of time and then make customers must prefer the new form.

\section{THE MEDIUM OF DIGITAL EXPRESSION}

There are many different kinds of expressions in digital fashion illustrations. It is convenient to make digital illustrations as a created tool, namely all the things we need are a computer and a painting tablet. If you install painting software, you can even combine Chinese paintings and oil paintings in one piece of art board naturally and harmoniously. The usage of digital technology makes fashion illustrations more attractive. We generally use the mediums of digital software are Photoshop, CorelDraw and Painter.

The expression of Photoshop: Photoshop can unlimitedly copy pictures, cut any shapes and collage perfectly to make illustrators draw their works imaginably. The most powerful function of Photoshop is filters that process the pictures fast to have some features that beyond reality, which create the effects are very creative with new vision. Illustrators can draw in traditional papers and scan them, then use tools of Photoshop to process their illustrations that is not only nimble and interesting like freehand drawing but also accurate and surreal in digital. 
The expression of CorelDraw: CorelDraw is a powerful vector-painting tool. It can process vector map and bitmap, cut patterns in someway such like cutting, combination, and connection. The result can be an image that has neat lines with a characteristic of strongly decorated. It can be used in handling lines in digital fashion illustrations.

The expression of Painter: Painter can be called natural brushes, which has a powerful painting function, flexible expressions and simulation painting effects, even it can mix the pigments in computer. This painting software includes natural painting tools like digital water colour brush, various artistic brushes, different kinds of twists, unpredictable special-effects and personal designed brush. Those tools can be combined with different texture art boards and make digital fashion illustration express its richer effects than traditional illustration.

\section{THE ARTISTIC STYLES OF FASHION ILLUSTRATION}

The research of art works is inseparable from the exploration of style, therefore, the artistic style of digital fashion illustration is to use modern digital technology to show the artist's creations of characteristics and their personal artistic attitudes. There are several types of digital fashion illustration, fashion beauty, grotesque doodle, minimalism, surrealism, magic, cartoon, graffiti, decorative style, gothic, etc.

The illustrations of fashion beauty are applied most widely with great impact that are expressions more of the life of urban white-collar workers in the middle class with Petty Bourgeoisie, such as fitness, shopping, hairdressing, go for a drive, chatting on the Internet, or kill time in a bar, which advocate a kind of high grade way of life. For example, the works of Jason Brooks have extremely strong modern-looking and elegant colour style that is filled with fashion culture in modern city and rich atmosphere in the middle class. He is good at layout using the principle of form beauty, S-shaped or symmetrical composition, and to contrast or harmonise the size, density, and rhythm in the structure of his illustrations. Jason Brooks created those works in CorelDraw, Photoshop, or Painter who prefers to use fashionable colour matching is usually vivid and bright. Moreover, the limbs proportions of human were being stretched deliberately and the features on the face were being exaggerated in his images. It can be seen that exaggerated big eyes made characters more pretty and vigorous; and slender limbs created an attraction of female to show their seductive charm. This type of illustrations has strongly visual impact that commonly used in commercial advertisings of perfume, garment, accessories, beauty and cosmetics.

The fashion illustration style of grotesque doodle usually have concise lines and obscure colours, in which illustrators often break the conventional composition and surreal expression to create strange, bizarre images. The major depicting contents of grotesque style reflect a part of young people hope to overturn the mainstream and to show their own unique worldview and outlook on life.

The works of the famous British fashion illustrator GRAHAM ROUNTHWAITE are quietly elegant in dark hues, in witch the garments look casual, the cities are common tough as a background, in addition to graffiti font to present a contrast of straight lines and curves, bold lines and filament, which is extremely characteristic and infectious in vision.

Minimalism fashion illustrations use a great number of simplified methods to grasp the momentums and features of objects in fashion in an instant, which seek not to have an accurate form, but often ignore the redundant details of the subject to achieve the goal of outstanding charm, such as the details of clothing or hands, feet, or mouth, nose. These ignorance make the images ethereal, vivid, charming, tasty, artistic. A Korean illustrator Enakei who created fashion illustrations with clear and loveliness colour, which have beautiful and fashionable form, smooth lines, distinct light and shade, so that the pictures are quite natural and unrestrained, neat and well-organised. His digital painting technology is very skilled with fashionable and charming brushstrokes, whose works are generally used in the shopping malls, packaging, and magazines, etc.(Figure 1)

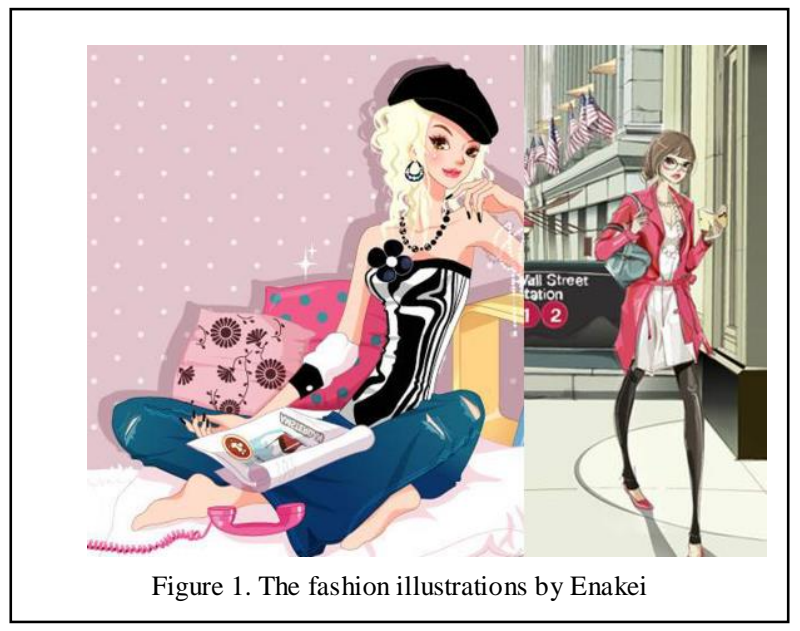

Surreal illustrators marks true photographs or material objects, where clothing and temperament, spirit, characteristics of people are pointed out in details, even a tiny change of structure and the change of light and shadow have been accounted clearly. They are fine-lined and plenty, elegant and simulated in the pen with the charm of color, and seek not relaxed and unrestrained. Surreal illustrations have strong sense of reality in the pictures and natural transition in the tone, in witch modeling factors even more typical than it really is, and, is full of idealism's perfection. French illustrator Melanie Delon pointed out characterisations are very exquisite with delicate and fair skin, resolute and determined eyes, to conveys the personality traits of the author herself. In addition to detailed characterisations, she depicted carefully peoples' surroundings and every objects in that 
environment, so that her pictures are always complete and agile, and a hit of old world. (Figure 2)

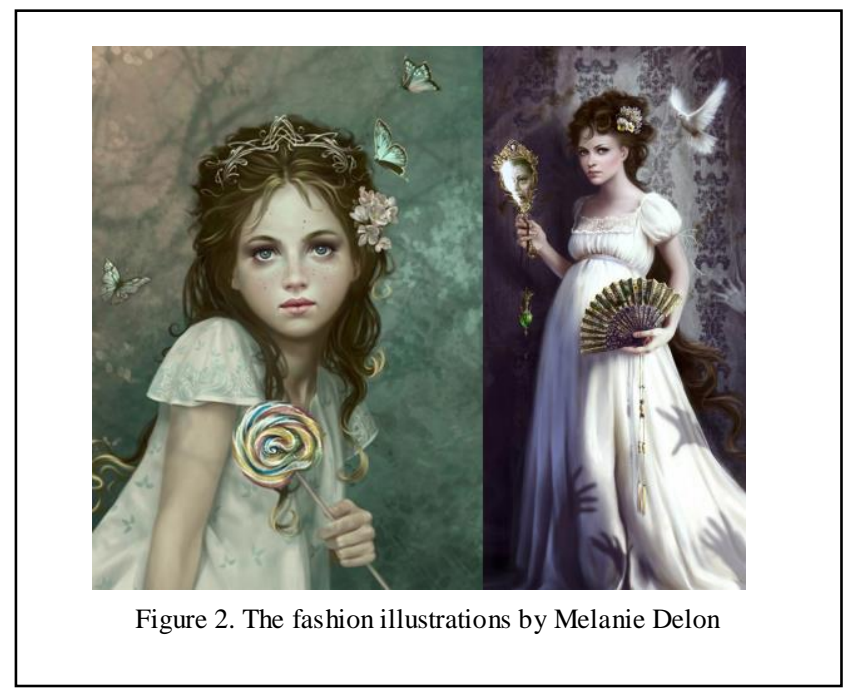

Magical Realism is one of the important characteristics of Latin American literature, which has a quite profound traditional culture origin of Latin America. On the other hand, magical style has been popular for illustration. Nowadays, this style is widely applied to the game posters, especially the set of game characters. It can be seen many of the online game characters are influenced by the style of magic. Japanese illustrator Calamaio who created illustrations have a strong magic sense in the colour matching. The illustrations by Indian illustrator Nisachar have magic modeling that made by Painter to present the sense of reality very strong in a magical picture.

Human body in proportion and the rhythm are mainly abandoned ruthlessly in the fashion illustration of Cartoon style, instead, personal emotions and preference of

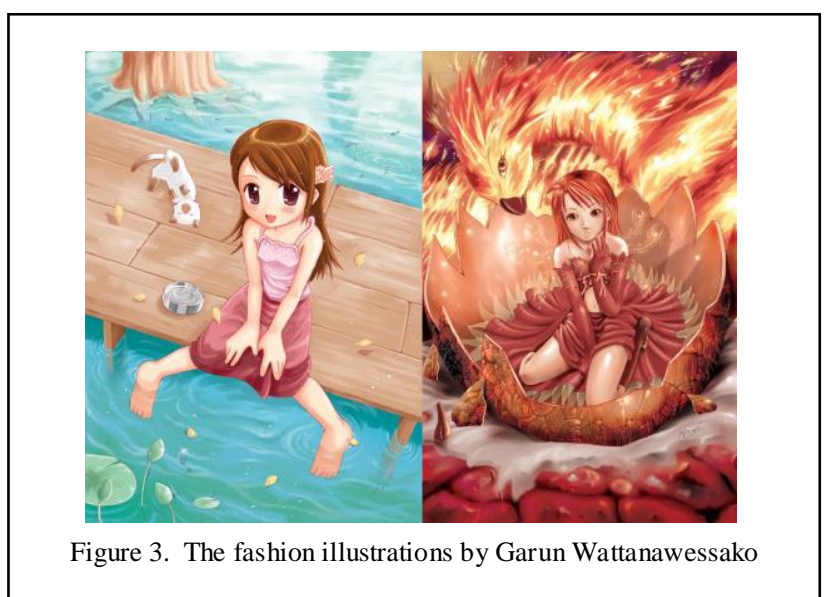

illustrators. This Style absorbs nutrition from cartoon, which is relatively suitable for showing of children and teens clothing. Thailand illustrator Garun Wattanawessako who created illustrations to show the girl's loveliness, and to exaggerate eyes to be cuter, and to present the performance of the environment is subtle, and what is more, we can see only skilled digital technology can the illustrator achieves such a sense of reality. (Figure 3)

Adornment style are given a new life via a medium of digital technology. It can be mechanical patterns with varieties of points, lines, and planes, or a kind of decorative patterns is transmogrified with the laws of beauty. Its colour schemes are fashionable novel, and the performance of decoration style has a strong subjective consciousness, with features of distortion, exaggeration, and decorative beauty. Such as Swedish illustrator Liselotte Watkins who put many sorts of elements, colours, and patterns together with what she has, but the mess are not toweling, instead, they are full of fashion. We can see that she has a strong ability to use software such as CorelDraw and Illustrator in her pictures.(Figure 4)

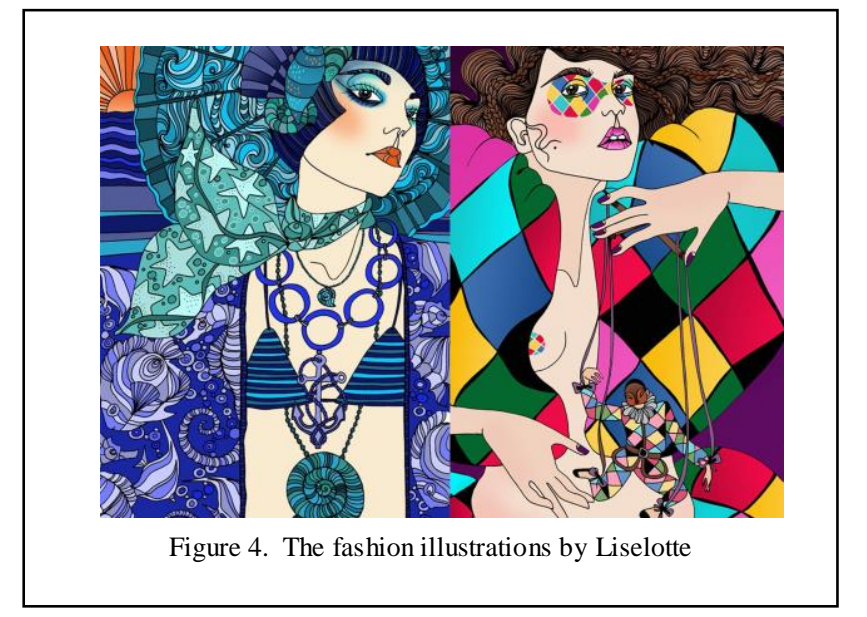

Gothic style of fashion illustration has the characteristics of lifeless colour, horror, and mystery. The theme always shows the fear of the darkness, the sorrow of death, forbidden love, and thoroughly pain to bring aesthetics feeling. In short, dark side exists in the world of human spirit. Gothic in the romanticism movement which was considered to correlate with darkness, bizarre, ghosts and so on. Japanese fashion illustrator Keegy who painted gothic puppet doll was deeply loved by people because of the form of having a unique style in the composition, emptiness in the images, and sharp contrast in colour.

In a word, traditional fashion illustration was endowed with such new life by digital technology. As it progresses beyond it's current stage, we believe that the digital fashion illustration will find an increasingly wide utilisation in many fields, and its styles will become more abundant in the future.

\section{REFERENCES}

[1] The Chinese academy of social sciences institute of language, The modern Chinese dictionary [M] The Commercial Press, 2002.

[2] Cihai [M]. Shanghai Dictionaries Press, 1989.

[3] J. Gu, digital art BBS [M]. Hangzhou: Zhejiang People's Fine Arts Publishing House, 2002.

[4] S. Li. Introduction to digital media art [M]. Beijing: Tsinghua University Press. 2006.

[5] Y. Zou, The techniques of Fashion Illustration [M] ., China textile \& apparel press, Beijing, 2009, pp. 130-136. 
[6] Q.Zhao, The Hand Painted Fashion Illustration [M] .,Liaoning Science and Technology Publish House, Shenyang, 2008,pp. 3841.

[7] J. He, The Application and Expression of digital fashion illustration [J]., article in a journal: Art Panorama, 2008, pp.20-21.
[8] J. Zheng, The Connection of Fashion Illustration and Traditional Illustration [J]., article in a journal: Beauty and Era, 2009(04), pp.15-16.

[9] Y. Liu, The Art Express and Aesthetics of Fashion illustration [J]., article in a journal: Decoration, 2009(01), pp.19-20.

[10] Y. Yao, The research of art and technique in fashion illustration [J]., article in a journal: Writer, 2011, pp. 22-23. 